\title{
EL ESTADO ACTUAL DEL PROTOCOLO A NIVEL JURÍDICO Y PROFESIONAL
}

\section{THE CURRENT STATE OF PROTOCOL FROM A JUDICIAL AND PROFESSIONAL PERSPECTIVE}

\author{
Javier Sierra Sánchez \\ Director del Departamento de Publicidad, Relaciones Públicas y Marketing de la \\ Facultad de Comunicación de la Universidad San Jorge. \\ Joaquín Sotelo González \\ Profesor de Estructura de la Comunicación en la Facultad de Ciencias de la Información \\ de la Universidad Complutense de Madrid
}

\section{Resumen}

El protocolo define las manifestaciones externas e internas de las estructuras del poder y es el instrumento que permite que el orden y la eficacia comunicativa organizacional se hagan presentes en el correcto desarrollo de determinados actos públicos y privados. A pesar de su creciente importancia, esta disciplina aún busca el lugar que desde nuestro punto de vista le corresponde en un triple nivel: científico, profesional y académico. A través de la técnica del método de investigación Delphi hemos tratado de recabar las opiniones de una serie de expertos en materia de protocolo con el objetivo de identificar teorías y tendencias al respecto de esta disciplina propia de las ciencias sociales. 


\title{
Palabras clave
}

Protocolo, método Delphi, actos oficiales, Real Decreto 200199/1983, universidad.

\begin{abstract}
Protocol defines the internal and external manifestations of power structures and it is the tool which enables effective organizational communication during public and private events. In spite of its growing importance, this discipline, from our point of view, is still searching for its own niche, which corresponds to three levels: scientific, professional and academic. By means of the Delphi method of research we have gathered together the opinions of a group of experts on protocol with the aim of identifying theories and trends relating to this Social Science discipline.
\end{abstract}

\section{Keywords}

Protocol, Delphi method, official events, Royal Decree 200199/1983, university.

\section{INTRODUCCIÓN}

Nos enfrentamos al estudio de una realidad compleja y multidimensional en la que todo o casi todo está por hacer. El objeto de estudio del protocolo en todas sus manifestaciones y niveles es enorme. Por lo tanto, el fin de nuestra presente aportación científica es necesariamente limitado. En este trabajo vamos a realizar un análisis del área jurídica y de la vertiente profesional del protocolo.

La aproximación al estudio del protocolo resulta dificultosa por tratarse de una disciplina escasamente tratada a nivel científico y académico. Además, posee una terminología confusa (ceremonial, protocolo y etiqueta) y en ocasiones mal definida y con poco rigor científico. López Nieto (1985:11) ya expresaba que es una “materia que tropieza con la dificultad de estar poco tratada, tanto doctrinal como legalmente, y en uno y otro caso, a través de una terminología confusa y poco definida”. 


\section{OBJETIVOS}

Entre los objetivos propuestos con nuestra labor investigadora destacaríamos los siguientes:

- Poner de manifiesto que el protocolo ha evolucionado y hoy no está circunscrito al área de aplicación de lo oficial, sino que ha traspasado esa frontera y hoy en día se emplea en otras esferas (empresarial, deportiva, universitaria, social, etc.).

- Detectar las deficiencias técnicas del Real Decreto 2099/1983 de Ordenación General de Precedencias del Estado.

- Analizar cuáles son los elementos que condicionan que un acto obtenga la consideración de oficial.

- Demostrar que el protocolo actual, que hemos decidido denominar del siglo XXI, ha roto las barreras en las que estaba encorsetado (esfera oficial) y su uso se ha extendido a otros ámbitos de aplicación. Actualmente el protocolo se aplica durante la celebración de actos públicos y privados.

- Analizar el Real Decreto 2099/1983 en profundidad para averiguar: si se sigue ajustando a la realidad social, política, económica y cultural treinta años después de su aprobación , si necesita algún tipo de reforma, si ésta debe ser total o parcial o por último reflexionar si es adecuado que una materia que regula la ordenación de personas físicas y jurídicas (Rey, reina, presidentes de las cámaras, Presidente del Gobierno) que están reflejadas en la Carta Magna de 1978 es suficiente que la regulación esté ejercida por un Real Decreto y no debiera ser objeto de regulación por parte de una L.O. ( Ley Orgánica)

- Conocer si existe una normativa protocolaria a nivel internacional que regule los procesos de comunicación entre los Estados.

- Averiguar cuáles son las competencias que debe poseer un jefe de protocolo para desarrollar adecuadamente su función.

- Descubrir qué universidades han optado por introducir el protocolo como asignatura universitaria en sus planes de estudio.

- Demostrar que la profesión del protocolo requiere un reconocimiento oficial a través de un estatuto jurídico que lo defina.

- Trataremos de averiguar en el Delphi y consultando a los expertos, cuáles deben ser las habilidades y competencias de los jefes de protocolo, en definitiva, trataremos de fijar el perfil 
profesional y personal de las personas que ocupan los cargos de responsabilidad protocolaria dentro de las organizaciones.

\section{METODOLOGÍA}

Para despejar dudas sobre el protocolo en sus aspectos jurídico y de formación hemos seleccionado el método Delphi. ¿Por qué hemos seleccionado el método Delphi? La base filosófica para este método prospectivo fue proporcionada por Helmer en 1972. Este autor argumentaba que en aquellos ámbitos donde no se han explicitado leyes científicas (como es en el caso del protocolo), el testimonio de expertos es permisible como fuente de conocimiento científico. El problema se reduce entonces a cómo tener y utilizar dicho testimonio o, más específicamente, a cómo combinar el testimonio de varios expertos en una declaración única.

Konow, Irene y Pérez Gonzalo (1990) señalan nítidamente dónde es apropiado aplicar este método:

“El método es apropiado para el estudio de los temas en los cuales la información, tanto del pasado como del futuro no se encuentra disponible en forma sintética y refinada; cuando esto ocurre, el método Delphi permite obtener dicha información y hacer uso de ella de forma más rápida y eficiente que los métodos tradicionales”.

Autores como Landeta (1999) también coincide en señalar la idoneidad de usar la técnica prospectiva del Delphi cuando:

-el problema no se presta al uso de una técnica analítica precisa; pero si puede beneficiarse de juicios subjetivos sobre bases colectivas.

- cuando se desea mantener la heterogeneidad de los participantes a fin de asegurar la validez de los resultados, se prefiere este método a los encuentros cara a cara.

- cuando no existe información disponible o la información con la que se cuenta es insuficiente, con este método se puede extraer la información que posea cada participante.

El estudio del Delphi es un sistema basado en una encuesta especializada e interactiva que nos permitirá visualizar con un grado importante de factibilidad el futuro posible, deseable y pertinente en materia de protocolo. Por lo tanto, el Delphi es un método prospectivo. La prospectiva es una de las herramientas más utilizadas para tratar de vislumbrar el futuro. Consiste en reunir las opiniones de diferentes personas (expertos), con el fin de identificar tendencias que se proyectan en un área de 
análisis, en este caso el protocolo. El proceso no pretende predecir el futuro, sino crear una visión consensuada del medio y largo plazo.

La consulta al panel de expertos se ha realizado en dos iteraciones por decisión previa. En la segunda iteración, cada miembro del panel tuvo la oportunidad de reconsiderar sus respuestas a la vista de su contestación inicial y la posición global del conjunto del panel al que pertenece.

Por lo tanto, la capacidad de predicción del Delphi se basa en la utilización sistemática de un juicio intuitivo emitido por un grupo de expertos. Es decir, el método Delphi procede por medio de la interrogación a expertos con la ayuda de cuestionarios sucesivos, a fin de poner de manifiesto convergencias de opiniones y deducir eventuales consensos. La encuesta se lleva a cabo de una manera anónima (actualmente es habitual realizarla haciendo uso del correo electrónico o mediante cuestionarios web establecidos al efecto) para evitar los efectos de "líderes". El objetivo de los cuestionarios sucesivos es disminuir el espacio intercuartil precisando la mediana.

Las preguntas se refieren, por ejemplo, a las probabilidades de realización de hipótesis o de acontecimientos con relación al tema de estudio (que en nuestro caso estarían relacionadas con la materia del protocolo). La calidad de los resultados depende, sobre todo, del cuidado que se ponga en la elaboración del cuestionario y en la elección de los expertos consultados.

De manera resumida, los pasos que se llevarán a cabo para garantizar la calidad de los resultados, para lanzar y analizar el Delphi, deberían ser los siguientes:

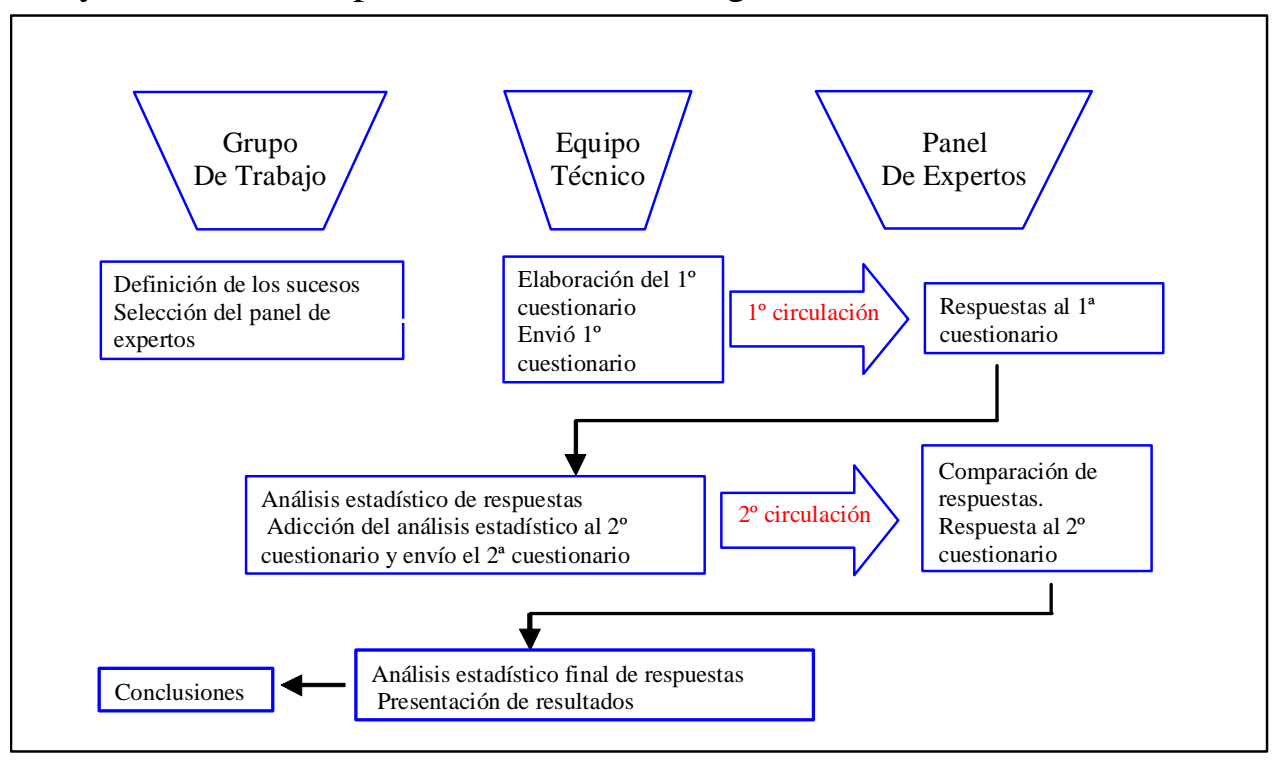

Figura 1: Esquema de las fases de desarrollo de un método Delphi. 
En este gráfico han quedado representadas gráficamente las fases y etapas; en definitiva, la forma de proceder para la aplicación de un método Delphi a un objeto de estudio cualquiera.

\section{AMBIGÜEDAD DE DEFINICIONES}

Dos factores han influido para que exista una ambigüedad terminológica a la hora de definir el protocolo:

los planteamientos normativistas carentes de fundamentación científica con los que ha sido tradicionalmente abordada esta realidad.

la multidisciplinariedad de esta disciplina (derecho, ciencias políticas, historia,

comunicación...)

Marchesi (1993:12) señala que cada autor de un libro de protocolo nos dará una definición diferente y cuanto más teórico sea, más larga y difícil de comprender será la explicación.

En este mismo sentido López Pérez (1990:157) indica la causa por la que, desde su punto de vista, existe esa variedad de definiciones.

“En la ley no existe una definición de lo que debe entenderse por protocolo, y esto ha motivado que los distintos autores que han escrito sobre el tema hayan formulado sus propias propuestas, que responden, como es lógico, a la idea que cada uno tiene sobre la materia”.

El propio Diccionario de la Real Academia Española, tampoco contribuye a clarificar el asunto, pues define "protocolo", como "la regla ceremonial o palatina establecida por decreto o costumbre»"

Benito (1996:4) cuando deja en esta definición: “conjunto de formalidades, determinadas por el protocolo, para cualquier acto público solemne" supeditado el ceremonial a los preceptos que de antemano (en la norma) ha prefijado el protocolo y así definía el ceremonial como el "conjunto de formalidades, determinadas por el protocolo, para cualquier acto público solemne”.

Por lo tanto, lo adecuado cuando queramos referirnos a la organización de actos, es hablar con propiedad y utilizar el vocablo protocolo. Puesto que la forma de proceder durante la celebración de un determinado evento está marcado por alguna norma o reglamento (del Estado, de una empresa, de una universidad, etc.). Lo que define Benito (1998:4) como ceremonial es lo que en el protocolo del

\footnotetext{
${ }^{1}$ Definición obtenida de la página http://www.rae.es
} 
siglo XXI debemos denominar como comunicación creativa. En este sentido normativo, LópezNieto (1985:20) enfatiza que:

“El Protocolo es una actividad, un quehacer, un acto o sucesión de actos, y que éstos pueden estar sujetos a las normas de protocolo que dicte el poder público o que se de a sí misma la entidad organizadora”.

\section{LOS ASPECTOS JURÍDICOS DEL PROTOCOLO}

Una de las fuentes de las que se sirve el protocolo son las leyes. De ahí, la importancia de dedicar un apartado extenso a analizar y estudiar las normas que tenemos que tener en cuenta a la hora de planificar un acto protocolario. Si este evento es realizado por la una institución pública, tendremos que tener muy en cuenta las normas que se encuentran recogidas en nuestro ordenamiento jurídico. Si por el contrario, el acto público tiene como emisor, otro tipo de organización (universidad, empresa, iglesia, ejército, deporte), tendremos que mirar si poseen normativa interna de protocolo o basarnos en otras fuentes de las que "bebe" el protocolo.

En cuanto a los usos sociales o reglas convencionales, debe señalarse que cada vez son más aceptadas en el protocolo, aunque teniendo en cuenta que varían según el territorio y la época. En este siglo XXI, los usos sociales no sólo han cambiado, sino que se plantea la necesidad de introducir nuevas maneras, que vienen impuestas por unos nuevos modos de vida, por la aparición de otras escalas de valores, por el cambio experimentado en la familia, por el papel que ejerce la mujer en la sociedad y por el impacto de las nuevas tecnologías en las formas de trabajar y comunicarse.

Las normas de protocolo obedecen todas, directa o indirectamente a un mismo fundamento, esto es, a la desigualdad de los hombres. A diferencia de lo que suele acontecer con la generalidad de las normas jurídicas, las del protocolo se fundamentan esencialmente en tales desigualdades. De tal modo nos sugiere López Nieto (1999) “Que no parece inexacto afirmar que, si todos los hombres fueran iguales, no podrían existir normas de protocolo".

López Nieto (1999:16) hace una distinción de normas que tradicionalmente se han considerado como protocolarias:

a) normas de carácter ético, representadas por aquellas que vienen exigidas por el cumplimiento del deber moral e inspiradas por la caridad o solidaridad para con los semejantes (p.e. la obligación de usar buenos modales). 
b) normas de carácter social o de etiqueta o simples reglas convencionales variables en el tiempo y en cada lugar, de carácter no vinculante y cuyo incumplimiento no supone para el infractor más que una infracción social (p.e. obligación de vestir chaqué de día y smoking por la noche).

c) normas con verdadero carácter jurídico, que son dictadas por el Estado o la Comunidad internacional, constituyendo ya derecho positivo ya derecho consuetudinario (p.e. la disposición que regula la precedencia de autoridades).

Atendiendo a las normas hasta ahora promulgadas, es preciso mencionar las siguientes, unas dictadas por el Estado y otras por las Comunidades normativa estatal puede agruparse de la siguiente manera según López-Nieto (1999:17):

1. Normas sobre concesión, rehabilitación y transmisión de títulos nobiliarios.

2. Normas sobre recompensas honoríficas: órdenes civiles y militares, medallas.

3. Normas reguladoras de símbolos del Estado: banderas, escudos e himnos.

4. Normas diversas que incluyen regulación de tratamientos honoríficos.

5. Normas sobre precedencias de autoridades e instituciones en los actos públicos.

6. Normas sobre celebración de actos, incluyendo la rendición de honores por las Fuerzas Armadas.

\subsection{Aspectos protocolarios derivados del Real Decreto 2099/1983 de 4 de agosto}

El Real Decreto 2099/1983, de 4 de agosto por el que se aprueba el Ordenamiento General de Precedencias en el Estado, tras su preámbulo, estipula claramente que el alcance de sus normas queda limitado a los actos estrictamente oficiales. Veamos cuáles son los principales aspectos que se derivan del Real Decreto 2099/1993 de 4 de agosto de Ordenación General de Precedencias del Estado:

1. Mayor valencia a las investiduras electivas y de representación que a las definidas por designación.

2. Mayor reconocimiento a las instituciones del mundo de la cultura.

3. Creó la Jefatura de Protocolo del Estado, encargada de aplicar las normas del mencionado ordenamiento.

4. División de actos oficiales en generales y especiales.

5. La presidencia será ocupada por la autoridad que organiza el acto. 
6. Confiere mayor prelación a la autoridad de la propia residencia.

7. Legaliza los usos y costumbres.

8. Establece tres rangos de ordenación: el individual o personal, el departamental y el colegiado.

9. No se reconoce la precedencia a la autoridad que se representa (sustituciones).

10. Establece el ordenamiento, tanto en actos celebrados en la Villa de Madrid, como en las Comunidades Autónomas.

11. Los Presidentes de las autonomías se ordenarán de acuerdo con la antigüedad de la publicación oficial del correspondiente Estatuto de Autonomía y en su caso por la antigüedad de los presidentes.

12. El alto personal que acompaña a SS.MM. los Reyes en actos oficiales se situarán en un lugar especial próximos a las reales personas, pero sin interferir el orden general y de precedencias.

13. Regula el ordenamiento de los Embajadores de España en el extranjero cuando representantes de los Gobiernos ante los que se han acreditado visiten oficialmente nuestro país.

14. Equipara al Presidente de la Diputación Foral de Navarra a los demás autonómicos, así como al Presidente del Parlamento Foral de Navarra a los de las Asambleas Legislativas de las Comunidades Autónomas.

El Real Decreto sobre la ordenación de precedencias ha cumplido su papel: propició en unos momentos de transición política en España y de caos protocolario lo que algunos autores han venido en denominar "la paz protocolaria”. Esto es cierto, pero en los últimos años, hemos asistido a una transformación sociopolítica de gran profundidad. Creemos que si el protocolo es reflejo de las estructuras políticas y organizacionales del Estado, mucho se ha trasformado el panorama que existía en España en 1983 con el que tenemos ahora en el 2008. La normativa de la transición debe dar paso a una nueva normativa, la de las autonomías. En la parte empírica de la investigación, interrogaremos a los expertos sobre si el Real Decreto 2099/1983 se ha quedado obsoleto debido:

- al devenir propio del desarrollo del Estado de las Autonomías y

- a las transformaciones políticas, económicas, sociales que se han producido en estos años desde su aprobación.

- al surgimiento de nuevas figuras/cargos que no están recogidos en la citada norma.

\subsection{Fuentes jurídicas del protocolo}


Para el profesor Carbajo ${ }^{2}$ (2006) las fuentes del protocolo actual son: las costumbres locales, las leyes, los reglamentos, los acuerdos internacionales, las tradiciones y los manuales.

Dreimann (1981:18-19) fundamenta el origen del protocolo diplomático en cuatro pilares, que a su vez son fuentes del protocolo:

1) El Derecho internacional consagrado por Westfalia (1648), (1815), Aachen (1818), Convención de La Habana (1928) y Convenciones de Viena (1961 y 1963).

2) El Derecho interno de cada Estado. Las actas consignadas deben ser observadas tanto por los órganos del Estado que las han dispensado como por los órganos de otros Estados en las relaciones internacionales. La norma legal estatal es en este sentido idéntica a la norma protocolaria, pero no es válida internacionalmente, ya que las otorgadas internamente por un Estado se diferencian formalmente y en su contenido de las de otros Estados.

3) Usos y costumbres internacionales. No conllevan ningún carácter de Derecho Internacional. Las normas de protocolo, por el contrario, que han sido elaboradas por la convivencia entre Derechos internacionales, son parte del Derecho Internacional, otorgadas en las Convenciones de Viena (1961 y 1963).

4) Tradiciones y peculiaridades nacionales. Estas reglas faltan en el compromiso jurídico, el elemento de conformidad con la práctica internacional habitual. Las normas protocolarías, que han sido separadas de tradiciones y peculiaridades nacionales, contradicen lo que el Estado y su historia simbolizan y representan. El menosprecio y la infracción de estás tradiciones se considera un daño para el Estado, y han de tenerse en cuenta en aras de las relaciones bilaterales.

Para López Pérez (1990) el fundamento jurídico del protocolo en España, está basado en dos pilares vitales:

la Constitución de 1978.

en el Real Decreto 2099, de 4 agosto de 1983.

A modo de síntesis podríamos formular que las fuentes del protocolo son: las costumbres o tradiciones, las normas y los documentos escritos (manuales, tesis doctorales y tratados) que hacen referencia a la disciplina.

\footnotetext{
${ }^{2}$ CARBAJO, Julio (2006) “Ordenamiento Jurídico Estatal”. Conferencia Impartida dentro del módulo I del XI Curso de Especialista en Protocolo y Ceremonial del Estado e Internacional. Escuela Diplomática de Madrid.
} 


\subsection{Sujetos del protocolo}

Para Dreimann (1981: 18), Miguel C. Díaz -Pache (1996:19) y Otero Alvarado (2000) consideran que el mayor “cliente-sujeto del protocolo” es la Administración del Estado en sus diferentes niveles: estatal, autonómica y local. Asimismo, la cada vez mayor implicación de presencias oficiales en actos organizados por instituciones privadas hace que ese protocolo acabe aplicándose en la mayoría de los casos en estas últimas. Por lo tanto, para estos autores el Protocolo sólo tiene sentido y aplicabilidad en los actos oficiales y en aquellos actos que no siendo oficiales participa alguna autoridad del Estado democrático y de derecho.

Así, nos encontramos en Otero Alvarado (2000: 28) con aseveraciones como la que mostramos a continuación en la que deja claro que sólo se puede hablar de protocolo cuando el sujeto emisor de la comunicación protocolaria sea el Estado: “El sujeto emisor de la comunicación protocolaria en esta norma ceremonial, al definirse exclusiva y alternativamente en esos dos ámbitos referidos, queda restringido al Estado, el único con capacidad de interacción en ellos”.

Sin embargo, nosotros creemos que esos planteamientos en el siglo XXI están ya caducos y un tanto obsoletos puesto que son muchos los autores que han distinguido diferentes tipos de protocolo en función de: el colectivo al que va dirigido ${ }^{3}$ y en base a la naturaleza de su función ${ }^{4}$, Urbina (1994: 30-33).

A partir de las aportaciones precedentes nosotros entendemos como sujetos del protocolo aquella persona de naturaleza física o jurídica que de forma activa o pasiva forma parte de un acto protocolario (independientemente de la tipología del mismo). Si en origen eran sujetos de protocolo todas las personas de diferente naturaleza física o jurídica que intervienen de forma activa o pasiva en la celebración de un acto oficial; hoy en día con los medios de comunicación de masas y con la apertura y modificación del sistema político, social y económico han incrementado el número de sujetos que pueden ser objeto del protocolo así como las esferas de ejecución.

Francisco Marín Calahorro (1997) insiste en que el término protocolo, concebido en su sentido más estricto, se refiere exclusivamente a los actos oficiales del Estado, tanto en su vertiente externa como interna. Sin embargo, este concepto se ha ampliado a otras esferas de aplicación, que también

\footnotetext{
${ }^{3}$ Así hablamos de protocolo de estado, protocolo oficial, protocolo diplomático, protocolo religioso, protocolo militar, protocolo empresarial, protocolo social y protocolo deportivo.

${ }^{4}$ Así hablamos de protocolo estructural, de gestión, de atención a personalidades y de eficacia personal.
} 
pueden considerarse sujetos de protocolo. Así, este mismo autor y en una de sus obras posteriores (2004:14) hace referencia a esa expansión de las barreras del protocolo:

“ El Ceremonial y el Protocolo, términos que hasta hace muy pocos años se utilizaban en actos estrictamente enmarcados en el ámbito de los actos oficiales del Estado, de las relaciones diplomáticas e intergubernamentales, de las actividades solemnes de las diferentes administraciones públicas y de determinadas instituciones, han ampliado su aplicación conceptual a, prácticamente , todas las áreas sociales. Entre ellas el mundo empresarial”.

A través de un proceso de inducción, a aseverar que: Sujetos del protocolo serán todas aquellas personas físicas y/o jurídicas que participan de alguna de estas modalidades de protocolo durante la celebración de un acto público: diplomático, religioso, político, judicial, militar, empresarial, social y deportivo.

\section{FUNCIONES Y PERSONAL DE UN DEPARTAMENTO DE PROTOCOLO}

Históricamente los regímenes y poderes políticos establecidos han considerado la información y la comunicación como un cuarto poder, capaz de influir sobre una gran cantidad de personas. Se han preocupado de lo que la opinión pública pensaba de la gestión realizada y por eso han necesitado siempre un organizador de su imagen y de sus apariciones públicas, y estas funciones han acabado materializándose en los Departamentos o Jefaturas de Protocolo.

Pero también podemos percibir que esa preocupación por el "cómo" hacer las cosas no ha trascendido en general al planteamiento teórico del "por qué” o el "para qué”, de forma que muchos profesionales que se desenvuelven en esta disciplina, todavía hoy están centrados en exceso en el orden de precedencias, la colocación de las banderas o la ubicación de ciertas autoridades no contempladas en el ordenamiento. Por lo tanto se centran demasiado en los aspectos técnicos del protocolo, olvidando la esencia comunicativa que conlleva la celebración de un acto.

La necesidad imperiosa de perfilar la actividad que se está llevando a cabo con absoluta pulcritud, lleva en ocasiones a no tener en cuenta que cualquier acción comunicativa no es más que el vehículo del mensaje a transmitir y no el mensaje en sí mismo, y se puede llegar a confundir el medio del que disponemos para conseguir nuestros objetivos con el objetivo mismo.

El protocolo define las manifestaciones externas e internas de las estructuras del poder, y es el instrumento que permite que el orden y la eficacia comunicativa organizacional se hagan presentes 
en el correcto desarrollo de los actos públicos (de cualquier tipo) y/o privados, que, en consecuencia, deben organizarse con profesionalidad.

Una de las funciones esenciales del protocolo es proyectar una determinada imagen de una organización (pública o privada) que es la organizadora del acto. El manejo de este intangible (la imagen e identidad corporativa) requiere de profesionales cualificados y altamente capacitados. La tarea de informar, anunciar y en definitiva de comunicar, es una tarea cada día más tecnificada y compleja. Requiere, por tanto, desde nuestro punto de vista, que la persona que vaya a desempeñar esa función posea una formación universitaria.

El compromiso de las instituciones públicas y/o privadas frente a sus stakeholders es de tal envergadura que no permite, sin paliativos, el que toda información, análisis, difusión, creación de imagen, relación con los públicos internos, externos y ambivalentes, concernientes o no, sea incorrectamente realizada por aficionados o, peor aún, por intrusos (buenos profesionales de otros campos que no conocen ni tienen la formación ni la experiencia suficientes para llevar a acabo las tareas de un responsable de protocolo).

Baschwitz Gómez de las Bárcenas (1997:81) enuncia que las actividades de comunicación de una organización deben estar en manos de profesionales correctamente formados. De ello deja constancia cuando confiesa:

"Las diferentes herramientas de comunicación (entre las que se encuentra el protocolo) ${ }^{5}$ utilizadas intercomunicada e interactivamente son una ciencia, una técnica y una arte. Su ejecución corresponde a profesionales especialmente formados para ello, que en su preparación previa han reunido en sí un conjunto de cualidades y conocimientos que los distinguen netamente de cualquier aficionado o intruso".

Esto lo han tenido muy claro tanto los departamentos de protocolo de las organizaciones ya sean públicas o privadas. Antes de organizar cada acto dan respuesta a dos preguntas: al porqué de la organización del acto y al para qué se quiere organizar ese acto. El común denominador de cada uno de los departamentos (ya sea oficial o empresarial) a la respuesta de los interrogantes (porqué y para qué) es sin duda la persecución de un fin para lo que tendrán que comunicar el mensaje de forma persuasiva.

Persuadir, claro está, pero introduciendo matices. Mientras que la persuasión del protocolo de los actos oficiales es ideológica/propaganda (única y exclusivamente) en los actos no oficiales, más

\footnotetext{
${ }^{5}$ Añadido por el investigador.
} 
propios del protocolo empresarial la persuasión puede tener dos fines: ideológicos o comerciales /publicitarios.

Correas (2004) en su obra incide en la importancia que el protocolo está adquiriendo en el ámbito empresarial, puesto que en cada acción que hace la empresa ésta crea una imagen. En este sentido las grandes empresas se están viendo obligadas a incorporar normativas o disposiciones internas capaces de poner orden en las apariciones públicas de sus responsables:

"Se hace necesaria una política de unificación de criterios no sólo en la organización de actos en cualquier sede del mundo sino en la forma de actuar en el quehacer del día a día y en la relación que mantiene con todos, o en las conductas que han de seguir sus directivos, o la atención a los invitados, o al manejo de los símbolos de la empresa, o la entrega de regalos”.

Por lo anteriormente señalado la política general de funcionamiento de las organizaciones están tratando de elaborar manuales internos de protocolo que no son otra cosa que un compendio de normas que establecen la forma de proceder para cada una de las situaciones y acciones de la organización. Una empresa, si quiere tener un buen intangible de identidad e imagen corporativa, no debe confiar el protocolo a una situación puntual de cada caso. Debe personalizar su propio protocolo y contribuir con ello a alcanzar la personalidad que le distinga claramente del resto de empresas y negocios.

Sobre el modo de organización de un departamento de protocolo poco, o casi nada hay escrito. Cada empresa en función de sus necesidades, tendrá un departamento más o menos grande, en cuanto al número de personas que lo puedan componer.

Vilarrubias (2005: 250 y siguientes) ofrece una visión sobre las habilidades, actitudes y aptitudes que debe poseer la persona que dirija un departamento de Protocolo:

“El departamento de protocolo debe estar dirigido por profesionales cuyo perfil incluya amplia formación cultural, conocimiento profundo de la práctica del protocolo, dominio del sistema en el que se estructuran los diferentes niveles de jerarquía social, creatividad, aptitudes psicológicas para las relaciones sociales $y$, dentro de éstas, grandes dosis de sentido común, para resolver con facilidad y lógica los problemas coyunturales que puedan presentarse durante la realización del acto”.

En referencia a las actitudes y carácter que deben estar presentes en los profesionales del protocolo Miguel Díaz Pache ${ }^{6}$ (1995:10) especifica las siguientes:

\footnotetext{
${ }^{6}$ En Revista Internacional de Protocolo Diciembre de 1995. núm.2
} 
“Una de las características básicas del profesional que aplique el protocolo ha de ser la flexibilidad y la sensatez, precisamente porque el protocolo no es una ciencia exacta y debe amoldarse a cada acto en particular. Su condición dinámica y en muchos casos innovadora hace indispensable que el profesional encargado de aplicar el protocolo tenga la formación adecuada y los conocimientos fundamentales para obtener como resultado el buen desarrollo de los acto”.

Vilarrubias (1994:209) profundiza aún más sobre la personalidad que debe poseer:

“Espíritu de servicio, sentido de la responsabilidad, don de gentes, discreción, integridad, diplomacia, habilidad, paciencia, comprensión, humanidad, sinceridad y rápida capacidad de decisión”. Y finaliza “... su armónica combinación con el vestir y el saber estar transmitiría el perfil humano de un buen jefe de protocolo, lo que se transmitiría en su actuar, logrando la confianza de los asistentes a los actos organizados y la credibilidad de sus decisiones”.

A partir de análisis y recopilación de diferentes manuales y artículos que enfocan el tema, consideramos que la gestión de un buen departamento de protocolo debe contar al menos con las siguientes categorías profesionales:

- Jefe o Director de Protocolo y Ceremonial

- Oficial de Protocolo

- Auxiliar e intérprete

\begin{tabular}{|l|c|}
\hline CATEGORÍA & $\begin{array}{c}\text { FORMACIÓN } \\
\text { ACADÉMICA ÓPTIMA }\end{array}$ \\
\hline Jefe o Director de Protocolo & $\begin{array}{c}\text { Doctor o Licenciado } \\
\text { preferentemente en Licenciaturas } \\
\text { Ciencias Sociales }\end{array}$ \\
\hline Oficial de Protocolo & $\begin{array}{c}\text { Diplomados Universitarios en } \\
\text { Ciencias Sociales }\end{array}$ \\
\hline Intérprete & $\begin{array}{c}\text { Licenciatura en Traducción e } \\
\text { Interpretación }\end{array}$ \\
\hline Auxiliares & F.P. y/o COU, Bachillerato. \\
\hline
\end{tabular}

Figura 2: Categorías y formación del personal de un “departamento tipo” de protocolo. 


\section{EL PROTOCOLO Y LA EDUCACIÓN UNIVERSITARIA}

La función de comunicar a través de los medios colectivos, en su doble faceta de informar y propagar es una tarea cada día más tecnificada y profesionalizada, que requiere una formación igualmente cada día más amplia y cualificada.

A expensas de demostrarlo empíricamente con el cuestionario que hemos ideado para aplicar el Delphi, consideramos que el protocolo encuentra su mejor acomodo dentro de las Ciencias Sociales en general- y dentro de las Ciencias de la Comunicación -en particular- . Y adentrándonos en un nivel más exhaustivo de análisis, se presenta como una herramienta eficaz de comunicación corporativa que pueden emplear las instituciones públicas y/o privadas.

Las disciplinas comunicativas nacieron en España como disciplinas universitarias hace poco más de treinta y cinco años y, surgidas de la práctica y para la práctica, demandan con urgencia una fundamentación epistémica amplia, por su hipertrofia en la práctica profesional y la creciente demanda en el ámbito académico de asignaturas especializadas, que exigen la ampliación teórica de estas disciplinas y su definitiva consolidación. El protocolo, como disciplina ligada a la comunicación social, a nivel macro y a la comunicación corporativa de las instituciones con ciertos tintes persuasivos, a nivel micro; comienza a reclamar en el ámbito académico su posición de fundamento epistemológico consolidado, como demuestra la introducción de la asignatura de protocolo en las facultades de Ciencias de la Comunicación en nuestro país.

Cabada del Rio (2004:72) indica que "las Ciencias de la Comunicación se constituyen y cobran sentido como disciplina cultural, en torno a un valor: la interacción social, en su acepción de unión de los entes sociales que componen el complicado engranaje social, conectando a las mismas con su dimensión psicosocial, interactiva y su dimensión pragmática y finalista, de corte social”.

Si entendemos el protocolo como una disciplina cultural que tiene un valor comunicativo social y una dimensión pragmática y finalista, de corte social; estaremos asimilando al protocolo dentro de las ciencias de la comunicación.

Uno de los objetivos que pretendemos en este trabajo, es analizar si las Facultades de Ciencias de la Comunicación de las universidades españolas ofrecen en sus ofertas formativas la disciplina del protocolo como asignatura dentro de las licenciaturas de ciencias sociales. Para ello, hemos realizado un estudio ${ }^{7}$ en el que analizábamos de todas las universidades que existen en España, cuántas de

\footnotetext{
${ }^{7}$ La totalidad del estudio se encuentra recogido en la parte de Anexos.
} 
ellas poseían estudios de Ciencias de la Comunicación. Asimismo, nos preocupamos de averiguar qué universidades dentro de los planes de estudio (específicos de Ciencias de la Información) ofrecían la posibilidad de cursar la asignatura de protocolo y en su caso, bajo qué modalidad se podía cursar (optativa, libre elección, obligatoria, troncal y postgrados).

Realizamos a continuación un resumen de los datos:

\begin{tabular}{|c|c|c|}
\hline $\begin{array}{l}\text { Total } \\
\text { universidades } \\
\text { españolas. }\end{array}$ & $\begin{array}{l}\mathrm{N}^{\circ} \text { de } \\
\text { universidades que } \\
\text { poseen estudios de } \\
\text { Ciencias de la } \\
\text { Información }\end{array}$ & $\begin{array}{l}\mathrm{N}^{\mathrm{o}} \text { de } \\
\text { universidades que no } \\
\text { poseen estudios de } \\
\text { Ciencias de la } \\
\text { Información. }\end{array}$ \\
\hline $\mathbf{7 5}$ & $\mathbf{4 1}$ & $\mathbf{3 4}$ \\
\hline
\end{tabular}

No en todas las universidades en las que existen estudios de Ciencias de la Información, tienen activada la asignatura de protocolo en alguna modalidad (optativa, libre elección u obligatoria). Hemos observado que en todas las facultades en las que aparece, es con carácter optativo. Vemos en la siguiente tabla que tan sólo once universidades, de las cuarenta y una que poseen estudios de Ciencias de la Información, ofertan la asignatura de protocolo en los planes de estudio ${ }^{8}$.

\begin{tabular}{|c|c|c|}
\hline \begin{tabular}{l}
\multicolumn{1}{c}{$\mathrm{N}^{\mathrm{o}}$ de } \\
universidades \\
que poseen \\
estudios de \\
Ciencias de la \\
Información
\end{tabular} & \begin{tabular}{l}
\multicolumn{1}{c}{$\mathrm{N}^{\mathrm{o}}$ de } \\
universidades \\
que poseen \\
estudios de \\
Ciencias de la \\
Información y \\
ofertan la \\
asignatura de \\
protocolo como \\
tr,op,ob y le \\
\end{tabular} & \begin{tabular}{l}
\multicolumn{1}{c}{$\mathrm{N}^{\mathrm{o}}$ de } \\
universidades que no \\
poseen estudios de \\
Ciencias de la \\
Información que no \\
ofertan la asignatura \\
de protocolo como \\
tr,op,ob y le
\end{tabular} \\
\hline 41 & 11 & 30 \\
\hline
\end{tabular}

Los datos tampoco son muy alentadores en las ofertas formativas de los programas de postgrado.

\begin{tabular}{|c|c|c|}
\hline $\begin{array}{l}\mathrm{N}^{\mathrm{o}} \text { total } \\
\text { universidades } \\
\text { españolas en las } \\
\text { que se puede } \\
\text { estudiar ciencias } \\
\text { de la } \\
\text { información }\end{array}$ & $\begin{array}{l}\mathrm{N}^{\mathrm{o}} \text { de } \\
\text { universidades } \\
\text { que ofrecen } \\
\text { estudios de } \\
\text { protocolo en } \\
\text { postgrados }\end{array}$ & $\begin{array}{l}\mathrm{N}^{\mathrm{o}} \text { de universidades } \\
\text { que no ofrecen estudios } \\
\text { de protocolo en } \\
\text { postgrados }\end{array}$ \\
\hline $\mathbf{4 1}$ & $\mathbf{1 0}$ & $\mathbf{3 1}$ \\
\hline
\end{tabular}

8 Los datos de este estudio han sido recabados de la página

http://www.rediris.es/recursos/centros/univ.es.html. Visitada el 8 de abril de 2005. 
En el estudio empírico trataremos de despejar incógnitas acerca de cuáles son las titulaciones universitarias más adecuadas para el ejercicio profesional y aplicación del protocolo. Asimismo los expertos de la materia protocolaria opinarán sobre el peso específico ${ }^{9}$ que debería tener el protocolo dentro de los planes de estudio de las titulaciones pertenecientes al ámbito de las Ciencias Sociales.

Los estudios de Protocolo han formado parte siempre -aunque no se haya reconocido así prácticamente- de la amplísima materia de la comunicación social. Y hasta que, Felio Vilarrubias, con la introducción del Protocolo como materia de estudio en los postgrados en la Universidad de Oviedo, o María Teresa Otero Alvarado, realizando la primera tesis doctoral sobre Protocolo, no se le ha empezado a otorgar a esta disciplina la importancia que debería tener en la comunidad universitaria y científica.

No se trataría por parte de la universidad, dar categoría universitaria a un mero tema de precedencias entre cargos públicos o personas poseedoras de un cierto rango que públicamente se les reconoce. No se trata de eso en absoluto en este siglo XXI. Desde nuestro punto de vista, la disciplina del protocolo ha salido del uso exclusivo de la esfera oficial a otras esferas y por consiguiente, afecta a un mayor número de personas. Se trata de respetar a las personas y las normas, en definitiva darles el honor que se merecen. Esto lleva aparejado igualmente el conocimiento de unos ciertos usos necesarios para dotar a las reuniones y actos en los que intervengan esas y otras personas, de la dignidad adecuada.

La celebración de cada acto protocolario supone una proyección de una imagen. Los efectos, consecuencias y los objetivos que queremos conseguir deben ser estudiados previamente por profesionales con titulación universitaria. Y eso puede y debe enseñarse en la universidad.

Es precisamente esa simbiosis entre tradición y progreso, respeto a la norma y capacidad de innovación (a través de las nuevas tecnologías y de los medios de comunicación de masas), lo que hace de la universidad el lugar idóneo para enseñar con el rango que corresponde, los contenidos de lo que entendemos por protocolo. Desde nuestro punto de vista, es innegable que en ese progreso del protocolo las TIC (Tecnologías de la Información y la Comunicación) y los medios de comunicación

\footnotetext{
${ }^{9}$ Los expertos en la pregunta 2.4 del cuestionario de la investigación empírica señalan el peso que el protocolo debe tener dentro de planes de estudios universitarios. El cuestionario está en la parte de Anexos.
} 
de masas, han jugado un papel decisivo en esa “democratización” ${ }^{10}$ el protocolo. Ha pasado de la esfera estrictamente oficial a otras esferas y ámbitos de aplicación.

Si tenemos claro que la universidad es el macro- contexto ideal en el que tiene asiento y cabida la ciencia social del protocolo; no menos claro nos debe quedar que las áreas de conocimiento más adecuadas para el ejercicio profesional y aplicación del protocolo, sean por tanto las áreas de Ciencias de la Comunicación. I protocolo es utilizado por los organismos públicos y privados como un instrumento de proyección de imagen. Lo que requiere de personal bien formado en Ciencias de la Comunicación con habilidades y competencias adecuadas para planificar qué es lo que una organización quiere proyectar (comunicar) en el exterior y para ello hay que tener un gran conocimiento de los medios de comunicación de masas ${ }^{11}$.

El protocolo de entidades públicas y privadas -como profesión- no debe quedar en manos de aficionados, sino de personas con la preparación académica necesaria, formadas en la universidad, dada la importancia creciente del tema y el nivel de conocimientos que se necesitan para actuar correctamente y saber dar respuesta, en casos conflictivos, a las dudas de tipo práctico que con frecuencia se plantean, sin ceder a presiones de ningún tipo, ni por defecto, ni por exceso.

Laforet (1997:207) alerta de la especial importancia que el protocolo tiene para las personas que cursan estudios superiores universitarios dentro de las facultades de Ciencias de la Comunicación (vertiente periodística) y avisa de la utilidad del conocimiento del protocolo para el profesional de la información en el desarrollo cotidiano de su labor informativa; dice a este respecto:

"Es por ello que, pese a ser una materia que se ha tratado y estudiado muy poco en el ámbito de las Ciencias de la Información, hoy aparece como un asunto al que investigadores y periodistas deben prestar un mayor interés, en especial por la utilidad practica que tiene para su trabajo cotidiano".

En la siguiente página ya apunta la necesidad de definir un plan de estudios oficial propio de la ciencia protocolaria o en su defecto vincular el estudio del protocolo al ámbito de las ciencias de la comunicación. Laforet (1997:208)

"En este sentido es necesario definir un posible plan de estudios con aquellas materias del protocolo que sean de interés para los profesionales de los medios de comunicación. El estudio de determinadas materias del protocolo, como la vexilología, la heráldica, los temas de precedencias,

\footnotetext{
${ }^{10}$ Entendemos por democratización dar a conocer a un mayor número de personas esta ciencia y extender el ámbito de aplicación de la esfera oficial a otros ámbitos como: el deportivo, el empresarial, el universitario.

${ }^{11} \mathrm{Y}$ de otras disciplinas que se estudian en cualquiera de las ramas de Ciencias de la Información.
} 
presidencias, representación oficial, organización de protocolo en España, Europa y en el mundo diplomático, así como ciertas tradiciones ceremoniales, facilitarán a los periodistas la comprensión de un lenguaje que les llevará a realizar con mayor facilidad y eficacia su tarea informativa”.

Este trabajo trata de abrir nuevas puertas universitarias al protocolo, desde la rama del conocimiento de ciencias de la comunicación, en la que puede engarzarse como hecho comunicativo de enorme incidencia social y en el mundo de la información.

Fernández Areal (2003:32) vincula claramente el protocolo con la comunicación “El Protocolo tiene mucho que ver con la Comunicación social, como ya dije, y entiendo que entra claramenteaunque no todo el mundo esté de acuerdo dentro del campo de las Relaciones Públicas ( Ciencias de la Información)” Dentro de ese artículo y unas páginas antes establece que “ el protocolo, el conocimiento de esas reglas, escritas o no, de relacionarse entre sí los seres civilizados, forma parte hoy, se quiera o no, y una parte importante, de lo que hemos dado en denominar Comunicación Social”

Batlle Mercadé (2005) afirma que "La difusión de actos ceremoniales de cualquier tipo deberán contar con un estudio minucioso - quizá incluso con la presencia y participación- de un profesional de protocolo (...) se hace imprescindible la formación de los informadores en los temas de protocolo aunque sea a nivel básico”

Existen autores que perciben el protocolo como parte fundamental de las ciencias de la comunicación. Tal es el caso de López Piñeiro (1997:168)

"Se toca fondo en el importante tema de los usos sociales. El protocolo, encargado de velar en todas las épocas por ellos, sufre en las horas del cambio, pero permanece atento, pues al final las reglas de cortesía y las ordenaciones de autoridades en el ceremonial, aunque varíen las épocas históricas, las demanda la sociedad. Entonces es cuando cobra vida e importancia el protocolo, porque tiene que aportar las soluciones técnicas a la nueva situación pues, al fin y al cabo, forma parte de la Ciencias de la Comunicación”.

Laforet (1997:54) vincula la necesidad de una formación en protocolo desde el área de Ciencias de la Información (desde la perspectiva de la labor del periodista):

“El presente trabajo aparece impulsado básicamente para establecer y ubicar el marco de una cuestión sobre la que, en un futuro inmediato, habrá que continuar profundizando y sistematizando sus contenidos y conocimientos, hasta lograr una disciplina que pueda llegar a estar perfectamente estructurada y definida, a la vez que ser adecuada para su transmisión como asignatura dentro de los estudios de Ciencias de la Información y como no de los de Protocolo a nivel universitario, como también ha manifestado el I Congreso de Oviedo”. 
Laforet (1997: 190) sigue insistiendo (línea de pensamiento que compartimos completamente) en la necesidad que tienen las empresas informativas de preparar a sus periodistas en materia de protocolo, pues ello les permitirá acceder a la interpretación de lo que constituye un auténtico lenguaje que se canaliza a través de determinadas normas y símbolos, así como a entender el comportamiento que, en determinadas ocasiones, adoptan autoridades y personalidades diversas.

\section{RESULTADOS OBTENIDOS EN LA APLICACIÓN DEL MÉTODO DELPHI.}

A continuación mostramos los resultados obtenidos a partir de las respuestas aportadas por los expertos en cada una de las preguntas del cuestionario que están divididas en dos apartados: jurídico y formación.

\subsection{Jurídico}

1.1. ¿Cree que el Real Decreto 2099/1983, de 4 de Agosto, por el que se aprueba el Ordenamiento General de Precedencias en el Estado se ajusta la realidad social, política, cultural y económica que estamos viviendo en este momento?

variable_1.1

\begin{tabular}{|c|l|c|c|}
\hline \multicolumn{2}{|c|}{ Casos } & Frecuencia & \% \\
\hline Válidos & 1 Nada & 5 & 13,2 \\
\hline & 2 Poco & 8 & 21,1 \\
\hline & 3 Neutral & 16 & 42,1 \\
\hline & 4 Mucho & 6 & 15,8 \\
\hline & 5 Muchísimo & 3 & 7,9 \\
\hline & Total & 38 & 100,0 \\
\hline
\end{tabular}

No existe consenso entre los expertos en este ítem. La tendencia que ha obtenido el mayor número de votos de los expertos ha sido la opción neutral. Es decir, 16 expertos han manifestado una postura neutral sobre si el R.D 2099/1983 de 4 de Agosto se ajusta a la realidad social, política, cultural y económica que se está viviendo en la actualidad El resto de los expertos se posicionan: 13 de ellos consideran que se ajusta poco o nada la realidad frente a 9 expertos que consideran que se ajusta bastante a la situación real.

1.2. El actual R.D 2099/1983 sobre precedencias del Estado que es la norma marco que regula el protocolo sólo admite la representación en el caso de que ésta sea delegada por el Rey o el Presidente del Gobierno. 
Esa potestad debería ampliarse a otras figuras del R.D. como por ejemplo Presidentes de Comunidades Autónomas variable_1.2

\begin{tabular}{|l|l|c|c|}
\hline \multicolumn{2}{|c|}{ Casos } & Frecuencia & \% \\
\hline Válidos & $\begin{array}{l}\text { 1 En total } \\
\text { desacuerdo }\end{array}$ & 13 & 34,2 \\
\hline & 2 En desacuerdo & 1 & 2,6 \\
\hline & 3 Neutral & 8 & 21,1 \\
\hline & 4 De acuerdo & 3 & 7,9 \\
\hline & $\begin{array}{l}\text { 5 Totalmente de } \\
\text { acuerdo }\end{array}$ & 13 & 34,2 \\
\hline & Total & 38 & 100,0 \\
\hline
\end{tabular}

A la hora de conocer lo que opinan los expertos sobre la posibilidad de ampliar la potestad de la representación o delegación no sólo al Rey o al Presidente del Gobierno existe de nueva, al igual que en la pregunta anterior, un nivel elevado de desacuerdo. Existen dos posturas antagónicas. Los expertos que creen que sí debería ampliarse esa potestad 16 expertos, otro grupo de expertos que consideran que no debería ampliarse 14 y otros que no lo tienen muy claro, 8.

1.3. El rango de ley otorgado a regular la materia protocolaria de precedencias debiera ser una Ley de Precedencias en lugar de un Real Decreto.

variable_1.3

\begin{tabular}{|l|l|c|c|}
\hline \multicolumn{2}{|c|}{ Casos } & $\begin{array}{c}\text { Frecue } \\
\text { ncia }\end{array}$ & \% \\
\hline Válidos & 1 En total desacuerdo & 3 & 7,9 \\
\hline & 2 En desacuerdo & 5 & 13,2 \\
\hline & 3 Neutral & 16 & 42,1 \\
\hline & 4 De acuerdo & 6 & 15,8 \\
\hline & 5 En total acuerdo & 8 & 21,1 \\
\hline & Total & 38 & 100, \\
& & & 0 \\
\hline
\end{tabular}

Acerca del rango de ley que le debería corresponder a la norma que regulase la materia protocolaria, los expertos muestran un nivel elevado de desacuerdo. Existen dudas por parte de los 
expertos (16 de ellos) sobre cuál debería ser el rango de ley que debiera regir los principios del protocolo. Son 8 expertos los que señalan que debe seguir siendo un Real Decreto el rango de ley que regule el protocolo. Sin embargo existe otro número de expertos, 14 , que creen que la materia que regula la precedencia del protocolo debería ser una ley de precedencias.

1.3.bis El R.D 2099/1983 General de Precedencias del Estado está en vigor desde su promulgación con unas leves modificaciones o retoques, si bien en algunos sectores, concretamente en las CC.AA. y Administración local, se están produciendo cambios en los últimos tiempos ha provocado un debate sobre la necesidad de su reforma. Indique el grado de modificación.

variable1.3_bis

\begin{tabular}{|l|l|r|r|}
\hline \multicolumn{2}{|c|}{ Casos } & $\begin{array}{r}\text { Fre } \\
\text { cuencia }\end{array}$ & \% \\
\hline Válidos & 2 Alguna modificación & 3 & 7,9 \\
\hline & 3 Neutral & 8 & 21,1 \\
\hline & 4 & 12 & 31,6 \\
\hline & 5 Modificaciones Relevantes & 15 & 39,5 \\
\hline & Total & 38 & 100, \\
& & & 0 \\
\hline
\end{tabular}

Es curioso observar cómo no existe consenso por parte de los expertos cuando se les pregunta si se ajusta o no el R.D. 2099/1883 a la realidad social, política, cultural y económica que estamos viviendo; pero sin embargo sí que existe un nivel elevado de consenso en señalar que la citada norma requiere algún tipo de modificación. Así lo señalan 27 expertos, el 71,1 \% de lo casos. Consideran que las modificaciones que se deben realizar en la norma son relevantes y sustantivas. Por lo tanto si el \% de consenso obtenido en este ítem es elevado es, que implícitamente, los expertos están considerando que en algo “está fallando" la norma que regula la precedencia protocolaria en cuanto a su adecuación con la realidad. Dato que nos llama la atención.

1.4. En el R.D. 2099/1983 deben contemplarse autoridades regionales y locales que no han sido incluidas en esta disposición y que surgieron posteriormente con el desarrollo de las autonomías.

variable_1.4

\begin{tabular}{|l|l|c|c|}
\hline \multicolumn{2}{|c|}{ Casos } & $\begin{array}{c}\text { Frecue } \\
\text { ncia }\end{array}$ & $\mathbf{\%}$ \\
\hline Válidos & 1 En total desacuerdo & 3 & 7,9 \\
\hline & 2 En desacuerdo & 1 & 2,6 \\
\hline & 3 Neutral & 7 & 18,4 \\
\hline & 4 De acuerdo & 7 & 18,4 \\
\hline & 5 En total acuerdo & 20 & 52,6 \\
\hline & Total & 38 & 100, \\
& & & 0 \\
\hline
\end{tabular}


En la pregunta anterior, los expertos ya manifestaban con una estabilidad elevada de respuesta y de consenso que el R.D. 2099/1983 necesitaba alguna reforma en su articulado. En esta pregunta detectamos una de las carencias de la norma. Los expertos en un cuantioso número, 27, están de acuerdo en considerar que deben ser incluidas en el Real Decreto autoridades regionales y locales que no fueron incluidas en la disposición cuando se aprobó y que han surgido posteriormente con el desarrollo de las autonomías.

1.5. Existe un vacío legal en el protocolo internacional

variable _1.5

\begin{tabular}{|l|l|c|c|}
\hline \multicolumn{2}{|c|}{ Casos } & Frecuencia & \% \\
\hline Válidos & 1En total desacuerdo & 1 & 2,6 \\
\hline & 3 Neutral & 18 & 47,4 \\
\hline & 4 De acuerdo & 7 & 18,4 \\
\hline & 5 En total acuerdo & 12 & 31,6 \\
\hline & Total & 38 & 100,0 \\
\hline
\end{tabular}

Los expertos no tienen muy claro si existe o no ese vacío legal. El 47,4 \% considera que no está claro si existe o no un vacío legal a nivel internacional. El 40\% de los expertos considera que existe un vacío legal. Con lo cuál, los expertos no nos despejan dudas a este respecto; debemos pensar por tanto que no existe una normativa clara o que ni siquiera existe normativa que regule el protocolo a nivel internacional.

1.6.1. Solamente el carácter de institución pública del que organiza el acto hace de él un acto oficial

1.6.2. El protocolo oficial es una herramienta al servicio exclusivamente del Estado en cualquiera de sus opciones (central, autonómico, local y los tres poderes: ejecutivo, legislativo y judicial)

variable_1.6.1

variable_1.6.2

\begin{tabular}{|l|l|c|c|l|c|c|}
\hline \multicolumn{2}{|c|}{ Casos } & Frecuencia & $\mathbf{\%}$ & \multicolumn{1}{c|}{ Casos } & Frecuencia & \% \\
\hline Válidos & $\begin{array}{l}\text { 1 En total } \\
\text { desacuerdo }\end{array}$ & 8 & 21,1 & 1 En total desacuerdo & 10 & 26,3 \\
\hline & 2 En desacuerdo & 12 & 31,6 & 2 En desacuerdo & 7 & 18,4 \\
\hline & 3 Neutral & 5 & 13,2 & 3 Neutral & 6 & 15,8 \\
\hline & 4 De acuerdo & 5 & 13,2 & 4 De acuerdo & 4 & 10,5 \\
\hline & 5 En total acuerdo & 8 & 21,1 & 5 En total acuerdo & 11 & 28,9 \\
\hline & Total & 38 & 100,0 & Total & 38 & 100,0 \\
\hline
\end{tabular}

No existe un acuerdo o consenso claro entre los expertos cuando se les pregunta, de forma implícita si sólo podemos hablar de protocolo, cuando éste es utilizado por los organismos y estamentos públicos. Y como vemos los expertos muestran un nivel elevado de desacuerdo. Existe un elevado grado de desacuerdo en las respuestas a las dos preguntas anteriormente señaladas. Por consiguiente no hay consenso y se dan posturas antagónicas: 
$\checkmark$ a la hora de señalar que exista una relación directa entre que el emisor sea una institución pública y que el acto se considere oficial.

$\checkmark$ a la hora de considerar el protocolo una herramienta de comunicación al servicio exclusivamente del Estado en cualquiera de sus opciones (central, autonómico, local y los tres poderes: ejecutivo, legislativo y judicial).

1.6.3. El protocolo del siglo XXI tiende al carácter mixto de los actos, es decir no hay una clara diferenciación entre los actos que son oficiales y aquellos otros que no lo son.

variable_1.6.3

\begin{tabular}{|l|l|c|c|}
\hline \multicolumn{2}{|c|}{ Casos } & Frecuencia & \% \\
\hline Válidos & $\begin{array}{l}\text { 1 En total } \\
\text { desacuerdo }\end{array}$ & 6 & 15,8 \\
\hline & 2 En desacuerdo & 6 & 15,8 \\
\hline & 3 Neutral & 8 & 21,1 \\
\hline & 4 De acuerdo & 11 & 28,9 \\
\hline & 5 En total acuerdo & 7 & 18,4 \\
\hline & Total & 38 & 100,0 \\
\hline
\end{tabular}

En esta pregunta, que está en relación con la 1.61. y la 1.6.2 ; observamos de nuevo el antagonismo de sus respuestas entre los expertos. Esto es una tendencia de lo que es y será el siglo XXI. Profesionales y expertos de la materia que siguen vinculando el protocolo a la esfera oficial y otro grupo que considera que el protocolo no puede ir ligado sólo a una parcela y tienen una idea del protocolo más aperturista. De este modo, vemos que no hay una gran diversidad de opiniones de los expertos a la hora de considerar que el protocolo del siglo XXI tiende al carácter mixto de los actos. Sin embargo podemos afirmar, ante la tendencia por el mayor número de expertos que se han posicionado en el acuerdo (18) frente a los expertos que se han posicionado en mostrarse en desacuerdo (12) con la tendencia al carácter mixto de los actos, que poco a poco se tiende a la apertura del protocolo de la esfera de lo oficial a otras esferas o ámbitos de aplicación. Esta afirmación se ve, de forma más nítida, en las respuestas que aportan los expertos en la siguiente pregunta.

1.6.4. El carácter oficial de un acto no solamente vendrá determinado por quién es jurídicamente quien organice el acto; sino también vendrá determinado por la finalidad y los asistentes al mismo. 
variable_1.6.4

\begin{tabular}{|l|l|c|c|}
\hline \multicolumn{2}{|c|}{ Casos } & $\begin{array}{c}\text { Frecuenc } \\
\text { ia }\end{array}$ & \% \\
\hline $\begin{array}{l}\text { Válid } \\
\text { os }\end{array}$ & 1 En total desacuerdo & 5 & 13,2 \\
\hline & 2 En desacuerdo & 3 & 7,9 \\
\hline & 3 Neutral & 3 & 7,9 \\
\hline & 4 De acuerdo & 13 & 34,2 \\
\hline & 5 En total acuerdo & 14 & 36,8 \\
\hline & Total & 38 & 100,0 \\
\hline
\end{tabular}

En esta pregunta, los expertos muestran un eminente grado de acuerdo al decidir por $71 \%$ de acuerdo que el carácter oficial de un acto no sólo viene determinado por quién es jurídicamente quien organiza el acto; sino que también vendrá determinado por la finalidad y los personas que asisten al mismo.

1.7. Las normas protocolarias de las CC. AA. deberían regular la precedencia únicamente de los cargos de la Comunidad Autónoma. Señale su grado de acuerdo con esta afirmación.

variable_1.7

\begin{tabular}{|l|l|c|c|}
\hline \multicolumn{2}{|c|}{ Casos } & Frecuencia & \% \\
\hline $\begin{array}{l}\text { Valid } \\
\text { os }\end{array}$ & $\begin{array}{l}\text { 1 En total } \\
\text { desacuerdo }\end{array}$ & 8 & 21,1 \\
\hline & 2 En desacuerdo & 1 & 2,6 \\
\hline & 3 Neutral & 3 & 7,9 \\
\hline & 4 De acuerdo & 6 & 15,8 \\
\hline & 5 En total acuerdo & 20 & 52,6 \\
\hline & Total & 38 & 100,0 \\
\hline
\end{tabular}

En esta variable, los expertos muestran un índice elevado de acuerdo, un 68,4\%, en el hecho de considerar que las comunidades autónomas en las leyes en las que desarrollan las precedencias en su territorio sólo deberían regular la precedencia protocolaria de los cargos de la comunidad autónoma.

1.8. En el supuesto que se elaborase una nueva ley que regulase el protocolo oficial, sería necesario que en la misma se reflejase con precisión y nitidez una definición exacta de protocolo. 
variable_1.8

\begin{tabular}{|l|l|c|c|}
\hline \multicolumn{2}{|c|}{ Casos } & $\begin{array}{c}\text { Frecuenc } \\
\text { ia }\end{array}$ & \% \\
\hline $\begin{array}{l}\text { Valido } \\
\mathrm{s}\end{array}$ & $\begin{array}{l}\text { 1 En total } \\
\text { desacuerdo }\end{array}$ & 4 & 10,5 \\
\hline & 2 En desacuerdo & 5 & 13,2 \\
\hline & 3 Neutral & 7 & 18,4 \\
\hline & 4 De acuerdo & 6 & 15,8 \\
\hline & 5 En total acuerdo & 16 & 42,1 \\
\hline & Total & 38 & 100,0 \\
\hline
\end{tabular}

No existe un acuerdo por parte de los expertos a la hora de fijar la necesidad o no de fijar en la ley que regula la precedencia del Estado una definición del término protocolo. El 57,9\% de los expertos considera que debe aparecer en la norma que regule el protocolo una definición exacta del término. Para el 23,7\% de los expertos muestran su desacuerdo con el hecho de que en la ley apareciera una definición. Y el 18,4 \% de los encuestados muestra una postura neutral al respecto. 


\subsection{Profesión}

2.1 Del cuadro que se muestra a continuación marque con una " $\mathrm{X}$ " las 10 características esenciales que usted considera que debe poseer un jefe de protocolo.

\begin{tabular}{|c|c|c|c|}
\hline CODIGO & CARACTERÍSTICAS & TOTAL & RANKING \\
\hline 2 & BUENA FORMACIÓN EN PROTOCOLO & 29 & 1 \\
\hline 5 & $\begin{array}{cccc}\text { CAPACIDAD } & \text { DE } & \text { REACCIÓN } & \text { Y } \\
\text { ANTICIPACIÓN } & & & \end{array}$ & 27 & 2 \\
\hline 8 & DISCRECIÓN & 24 & 3 \\
\hline 1 & EXPERIENCIA & 18 & 4 \\
\hline 14 & CAPACIDAD DE IMPROVISACIÓN & 18 & 5 \\
\hline 7 & CAPACIDAD DE CONSENSO & 17 & 6 \\
\hline 10 & AMABILIDAD & 17 & 7 \\
\hline 11 & $\begin{array}{c}\begin{array}{c}\text { DOTES COMUNICATIVAS } \\
\text { verbal) }\end{array} \\
\text { (verbal/no }\end{array}$ & 17 & 8 \\
\hline 12 & CAPACIDAD DE TRABAJO EN EQUIPO & 17 & 9 \\
\hline 13 & SENTIDO COMÚN & 16 & 10 \\
\hline 14 & CAPACIDAD DE LIDERAZGO & 14 & 11 \\
\hline 15 & ORGANIZADO & 14 & 12 \\
\hline 3 & LEALTAD & 13 & 13 \\
\hline 4 & MANEJO DE VARIOS IDIOMAS & 13 & 14 \\
\hline 9 & TEMPLANZA & 12 & 15 \\
\hline 10 & BUENA PRESENCIA & 11 & 16 \\
\hline 13 & PRUDENCIA & 10 & 17 \\
\hline 14 & FORMACIÓN UNIVERSITARIA & 10 & 18 \\
\hline 15 & FLEXIBILIDAD & 9 & 19 \\
\hline 16 & SABER ESTAR & 9 & 20 \\
\hline 4 & AUTORIDAD & 8 & 21 \\
\hline 6 & CAPACIDAD DE RECICLAJE & 6 & 22 \\
\hline 7 & HONRADEZ & 6 & 23 \\
\hline 12 & PACIENCIA & 5 & 24 \\
\hline 13 & GANAS DE TRABAJAR & 5 & 25 \\
\hline 14 & EFICAZ & 5 & 26 \\
\hline 15 & RESPETUOSO & 4 & 27 \\
\hline 16 & CORTÉS & 4 & 28 \\
\hline 17 & CONOCIMIENTOS JURÍDICOS & 4 & 29 \\
\hline 18 & SABER DELEGAR & 4 & 30 \\
\hline 19 & TOLERANTE & 3 & 31 \\
\hline 20 & SENTIDO DEL HUMOR & 3 & 32 \\
\hline 11 & FIRMEZA & 2 & 33 \\
\hline 12 & DINÁMICO & 2 & 34 \\
\hline 13 & ESCUCHA ACTIVA & 2 & 35 \\
\hline 14 & ADAPTABILIDAD & 1 & 36 \\
\hline 15 & CARISMÁTICO & 0 & 37 \\
\hline
\end{tabular}

En la primera iteración se les instó a los expertos a que indicaran, según su criterio cualificado, cuáles eran las cuatro características y competencias que debía poseer un jefe de protocolo. En la 
segunda iteración y recogiendo las características que habían señalado los expertos por separado, elaboramos un cuadro resumen para poder cuantificar las respuestas que se habían dado en la iteración 1. Así quedaron configuradas para la segunda iteración un total de 37 actitudes que debía poseer un buen jefe de protocolo. Para ser más analíticos y fijar con mayor precisión y lograr un mayor grado de consenso se les pidió que eligieran de las 37 características, las cuatro que ellos consideraban como imprescindibles. Finalmente los resultados que se obtuvieron quedan reflejados en la tabla anterior. Nosotros, a partir de los resultados obtenidos por los expertos hemos agrupado las características y competencias que debe poseer un jefe de protocolo como: fundamentales, básicas, complementarias y adicionales no imprescindibles.

\begin{tabular}{|c|c|c|c|}
\hline Fundamentales & Básicas & Complementarias & $\begin{array}{l}\text { Adicionales } \\
\text { no } \\
\text { imprescindibl } \\
\text { es }\end{array}$ \\
\hline $\begin{array}{l}\text { Buena } \\
\text { formación en } \\
\text { protocolo }\end{array}$ & Experiencia & Sentido Común & Autoridad \\
\hline $\begin{array}{l}\text { Capacidad de } \\
\text { reacción y } \\
\text { anticipación }\end{array}$ & $\begin{array}{l}\text { Capacidad de } \\
\text { improvisación }\end{array}$ & $\begin{array}{l}\text { Capacidad de } \\
\text { liderazgo }\end{array}$ & $\begin{array}{l}\text { Capacidad de } \\
\text { reciclaje }\end{array}$ \\
\hline \multirow[t]{14}{*}{ Discreción } & $\begin{array}{l}\text { Capacidad de } \\
\text { consenso }\end{array}$ & Organizado & Honradez \\
\hline & Amabilidad & Lealtad & Paciencia \\
\hline & $\begin{array}{l}\text { Dotes } \\
\text { comunicativas } \\
\text { (verbal/no } \\
\text { verbal) }\end{array}$ & $\begin{array}{l}\text { Manejo de varios } \\
\text { idiomas }\end{array}$ & $\begin{array}{ll}\text { Ganas } & \text { de } \\
\text { trabar } & \end{array}$ \\
\hline & $\begin{array}{l}\text { Capacidad de } \\
\text { trabajo en } \\
\text { equipo }\end{array}$ & Templanza & Eficaz \\
\hline & & Buena presencia & Respetuoso \\
\hline & & Prudencia & Cortés \\
\hline & & $\begin{array}{l}\text { Formación } \\
\text { Universitaria }\end{array}$ & $\begin{array}{l}\text { Conocimientos } \\
\text { jurídicos }\end{array}$ \\
\hline & & Flexibilidad & Saber delegar \\
\hline & & Saber estar & Tolerante \\
\hline & & & $\begin{array}{l}\text { Sentido del } \\
\text { humor }\end{array}$ \\
\hline & & & Firmeza \\
\hline & & & Dinámico \\
\hline & & & Escucha activa \\
\hline & & & Adaptabilidad \\
\hline
\end{tabular}

Figura 3: Características y competencias que debe poseer un jefe de protocolo 
2. 2. Los valores esenciales que se desprenden de la correcta aplicación de las normas de protocolo son la justicia y el orden.

variable_2.2

\begin{tabular}{|l|l|c|c|}
\hline \multicolumn{2}{|c|}{ Casos } & Frecuencia & \% \\
\hline Válidos & 2 En desacuerdo & 7 & 18,4 \\
\hline & 3 Neutral & 9 & 23,7 \\
\hline & 4 De acuerdo & 8 & 21,1 \\
\hline & 5 En total acuerdo & 14 & 36,8 \\
\hline & Total & 38 & 100,0 \\
\hline
\end{tabular}

En esta pregunta existe una tendencia por parte de los expertos a considerar que los valores que se desprenden de la correcta aplicación del protocolo son la justicia y el orden, pero no únicamente. El 57,9\% de los expertos están de acuerdo que los valores que se desprenden de la aplicación del protocolo son la justicia y el orden frente a un 18,4 \% de encuestados que no consideran que sean esos dos valores los que se desprenden de la aplicación de las normas de protocolo. Un 23,7\% muestran una actitud neutral acerca de que los valores que se desprendan del protocolo sean los citados anteriormente.

2.3. En los próximos años la profesión del protocolo requiere un reconocimiento oficial, a través de un estatuto jurídico que la defina.

variable_2.3

\begin{tabular}{|l|l|c|c|}
\hline \multicolumn{2}{|c|}{ Casos } & Frecuencia & \% \\
\hline Validos & 2 En desacuerdo & 2 & 5,3 \\
\hline & 3 Neutral & 5 & 13,2 \\
\hline & 4 De acuerdo & 5 & 13,2 \\
\hline & 5 En total acuerdo & 26 & 68,4 \\
\hline & Total & 38 & 100,0 \\
\hline
\end{tabular}

En esta cuestión existe un elevado consenso entre los especialistas de la materia protocolaria a la hora de afirmar que la profesión del protocolo requiere un reconocimiento oficial a través de un estatuto jurídico que la defina. En este sentido se expresaron el 81,6\% de los casos. El 13,2\% de los expertos mantuvo una postura neutral en este sentido y tan sólo dos personas de la muestra manifestaron su desacuerdo con el hecho de que la profesión del protocolo requiera un reconocimiento oficial a través de un estatuto jurídico que la defina. 


\section{FUTURAS LÍNEAS DE INVESTIGACIÓN}

Si partimos del hecho real de que el protocolo es una disciplina con una consolidada tradición histórica, pero poco analizada desde el punto de vista científico, no es de extrañar que aún quede mucho por hacer en la sistematización del conocimiento de esta materia.

Ofrecemos a continuación posibles líneas de investigación que han surgido de las conclusiones de esta modesta investigación pero de gran rigor desde el punto de vista metodológico

El estudio de la implantación de las nuevas tecnologías en el quehacer profesional del protocolo.

Elaboración de un estudio de los actos protocolarios que organizan las instituciones por sectores de actividad. Asimismo investigar en los fines que persiguen las organizaciones cuando organizan un acto protocolario. Buscar qué elementos son los que inducen a las instituciones a organizar actos públicos.

- Desde el punto de vista jurídico: seguir ahondando en los cambios y/o modificaciones que requiere el Real Decreto 2099/1983 y buscar los elementos que determinan que un acto sea considerado oficial.

- Dentro de la comunicación social en valores, averiguar cuáles son los valores que se desprenden de la correcta aplicación del protocolo.

- $\quad$ Análisis de la profesión protocolaria por sectores: públicos y privados.

- $\quad$ Elaboración de $\quad$ En estudio de protocolo comparado a nivel europeo.

\section{BIBLIOGRAFÍA}

ARCEO, J.L. (1999) (Director): Tratado de Publicidad y Relaciones Públicas. ICIE. Madrid. Universidad Complutense de Madrid.

BASCHWITZ GÓMEZ DE LAS BÁRCENAS, A.L. (1997): Las RR.PP. integrales como concepto aglutinador de las herramientas en una concepción moderna de la comunicación social. Tesis Doctoral. 
BATLLE MERCADÉ, P. (2005): “Protocolo y Medios de Comunicación” Conferencia Impartida en la Escuela Diplomática en el Módulo II del XI Curso de Especialista en Protocolo y Ceremonial del Estado e Internacional

BENITO SACRISTÁN, P. (1996): Manual de Protocolo para las entidades locales. Madrid, Comunidad Autónoma.

BUCETA FACORRO, L. (1992): Fundamentos psicosociales de la información. Madrid. Edit. Centro de estudios Ramón Areces.

CABADA DEL RÍO, M. (2001): Actualización psicosociológica de las relaciones públicas. Tesis doctoral. Facultad de Ciencias de la Información. CAVP II.

-(2004): Análisis psicosocial de la comunicación audiovisual de masas actual. Tesis doctoral. Facultad de Psicología.

CARBAJO, J. (2006): “Ordenamiento Jurídico Estatal”. Conferencia Impartida dentro del módulo I del XI Curso de Especialista en Protocolo y Ceremonial del Estado e Internacional. Escuela Diplomática de Madrid.

CORREAS SÁNCHEZ, G. (2004): La empresa y su protocolo: el procedimiento de calidad en la organización de sus actos. Madrid. Editorial. Protocolo.

DÍAZ-PACHE PUMAREDA, M. (1995): “Protocolo del Estado: coordinación de actos” en Revista Internacional de Protocolo, núm. 1, septiembre 1995. Págs. 23 - 24.

-(1996): “Las grandes actuaciones protocolarias del año 1992 desde Protocolo de Estado” en VV.AA. El protocolo avui. El protocolo hoy. Barcelona.

DREIMANN, D. (1981): Das Diplomatische Protokoll. Leipzig. Koehler und Amelang.

FERNÁNDEZ, F. (2004): Ceremonial y Protocolo: Guía Completa. Madrid. Editorial. Oberon. 
HELMER, O. \& RESCHER, N. (1972): “Sobre epistemología de las ciencias inexactas” en Futuro y Presente núm. 8. Págs. 115-135.

KONOW, I. \& PÉREZ, G. (1990): Métodos y técnicas de investigación prospectiva para la toma de decisiones. Chile. Editorial. Fundación de Estudios Prospectivos. Universidad de Chile.

LAFORET, J. J. (1997): Protocolo y Medios de Comunicación Social. Canarias. Editorial Premon.

LANDETA, J. (1999): El método Delphi. Una técnica de previsión para la incertidumbre. Barcelona. Editorial Ariel.

LINSTONE, H., TUROFF,M.(1975): The Delphi Method. Techniques and Applications. AddisonWesley, pág.3

LÓPEZ NIETO, F. (1985): Honores y Protocolo. Madrid. El Consultor de los Ayuntamientos y de los Juzgados.

- (1995): Manual de Protocolo. Barcelona, Editorial Ariel.

- (1999): Legislación de Protocolo. Madrid, editorial Dykinson.

- (2000): Honores y Protocolo (2 tomos).Madrid.

LÓPEZ PÉREZ, C. (1990). El libro del saber estar. La urbanidad y los usos sociales. Oviedo, ediciones Nobel.

LÓPEZ PIÑEIRO, R. (2003): “El protocolo en las instituciones públicas” en FERNÁNDEZ AREAL, M. (dir) (2003) Relaciones Públicas y Protocolo. IV Jornadas de Comunicación Social. Universidad de Vigo.

MARCHESI, M. R. (1992). El Protocolo hoy. Madrid, El País-Aguilar.

MARÍN CALAHORRO, F. (1997): Fundamentos del Protocolo en la comunicación Institucional. Madrid, Editorial Síntesis.

- (2000): Protocolo y Comunicación. Los medios en los actos públicos. Barcelona. BAYER HNOS. S.A. 
- (2004): El protocolo en los actos de empresa. La gestión de eventos corporativos. Madrid. Editorial Fragua.

- (2006): Protocolo y comunicación. Barcelona. Editorial Bayer Hermanos.

OTERO ALVARADO, Ma . T. (1999): Protocolo y relaciones públicas de Estado. Los días nacionales en la exposición Universal de Sevilla. Tesis Doctoral

- (2000): Teoría y Estructura del Ceremonial y el Protocolo. Sevilla, Ed. Mergablum.

PUMAR VÁZQUEZ, J. (1990): Guía de Ceremonial y Protocolo. Santiago de Compostela, Caixa Galicia, $2^{\text {a }}$ edición

SIERRA SÁNCHEZ, J. (2008): “Protocolo: herramienta comunicativa persuasiva y simbólica” en Revista ZER. Núm.24 Mayo 2008.

VILARRUBIAS, F.A. (1994): Tratado de Protocolo del Estado e Internacional. Oviedo, Ediciones Nobel.

- (2005): Protocolo, ceremonial, heráldica y vexilología en el Estado, en las corporaciones públicas y en la empresa internacional. Oviedo. Ediciones Nobel. 


\section{ANEXOS \\ 8.1. Cuestionario utilizado en el método empírico INFORMACIÓN Y FORMACIÓN}

Código: 02

a) Edad:

b) Sexo: $\square$ Hombre Mujer

c) ¿Es funcionario o libre designación? Señale con una "X" la opción. funcionario $\quad \square$ libre designación $\quad$ ambos $\square$

d) ¿Qué grado de estudios posee? Señale el de mayor rango.
EGB $\square$
C.O.U.
Diplomado
Licenciado $\square$
Doctor
Ingeniero $\square$
Arquitecto
e) Sólo si cursó estudios universitarios indique el nombre de la licenciatura que terminó.

f) Indique el nombre de la universidad en la que se licenció

\section{Bloque I. JURÍDICO}

1.1. ¿Cree que el Real Decreto 2099/1983, de 4 de Agosto, por el que se aprueba el Ordenamiento General de Precedencias en el Estado se ajusta la realidad social, política, cultural y económica que estamos viviendo en este momento?
Nada
12
3
4
$5 \quad$ Muchísimo

1.2 El actual R.D 2099/1983 sobre precedencias del Estado que es la norma marco que regula el protocolo solo admite la representación en el caso de que ésta sea delegada por el Rey o el Presidente del Gobierno. Esa potestad debería ampliarse a otras figuras del R.D. como por ejemplo Presidentes de Comunidades Autónomas
En total desacuerdo 1
2

$3 \quad 4$
5 En total acuerdo

1.3 El rango de ley otorgado a regular la materia protocolaria de precedencias debiera ser una Ley de Precedencias en lugar de un R.D
En total desacuerdo 1
2
3
4
5 En total acuerdo

1.3. bis. El R.D 2099/1983 General de Precedencias del Estado está en vigor desde su promulgación con unas leves modificaciones o retoques, si bien en algunos sectores, concretamente en las CC.AA. y Administración local, se están produciendo cambios en los últimos tiempos ha provocado un debate sobre la necesidad de su reforma. Indique el grado de modificación. 


$\begin{array}{lllllll}\begin{array}{l}\text { Modificaciones } \\ \text { Irrelevantes }\end{array} & 1 & 2 & 3 & 4 & 5 & \begin{array}{l}\text { Modificaciones } \\ \text { Relevantes }\end{array}\end{array}$

1.4. En el R.D. 2099/1983 deben contemplarse autoridades regionales y locales que no han sido incluidas en esta disposición y que surgieron posteriormente con el desarrollo de las autonomías.

En total desacuerdo $1 \quad 2 \quad 2 \quad 3 \quad 4 \quad 4 \quad 5 \quad$ En total acuerdo

1.5. Existe un vacío legal en el protocolo internacional
En total desacuerdo 1
$2 \quad 3 \quad 4$
5 En total acuerdo

1.6.1 Solamente el carácter de institución pública del que organiza el acto hace de él un acto oficial
En total desacuerdo 1
2
5 En total acuerdo

1.6.2 El protocolo oficial es una herramienta al servicio exclusivamente del Estado en cualquiera de sus opciones (central, autonómico, local y los tres poderes: ejecutivo, legislativo y judicial)
En total desacuerdo 1
23
4
5 En total acuerdo

1.6.3 El protocolo del siglo XXI tiende al carácter mixto de los actos, es decir no hay una clara diferenciación entre los actos que son oficiales y aquellos otros que no lo son.
En total desacuerdo 1
23
4
5 En total acuerdo

1.6.4 El carácter oficial de un acto no solamente vendrá determinado por quién es jurídicamente quien organice el acto; sino también vendrá determinado por la finalidad y los asistentes al mismo.
En total desacuerdo 1
$2 \quad 3 \quad 4$
5 En total acuerdo

1.7 Las normas protocolarias de las CC. AA. deberían regular la precedencia únicamente de los cargos de la Comunidad Autónoma. Señale su grado de acuerdo con esta afirmación.

$$
\text { En total desacuerdo } \quad 1 \quad 2 \quad 3 \quad 3 \quad 4 \quad 5 \quad \text { En total acuerdo }
$$

1.8 En el supuesto que se elaborase una nueva ley que regulase el protocolo oficial, sería necesario que en la misma se reflejase con precisión y nitidez una definición exacta de protocolo.

$$
\text { En total desacuerdo } \quad 1 \quad 2 \quad 3 \quad 3 \quad 4 \quad 5 \quad 5 \quad \text { En total acuerdo }
$$

\section{Bloque II. PROFESIÓN}

2.1Del cuadro que se muestra a continuación marque con una " $X$ ” las 10 características esenciales que usted considera que debe poseer un jefe de protocolo.

\begin{tabular}{|r|l|l|}
\hline 1 & EXPERIENCIA & \\
\hline 2 & BUENA FORMACIÓN EN PROTOCOLO & \\
\hline 3 & LEALTAD & \\
\hline 4 & AUTORIDAD & \\
\hline 5 & CAPACIDAD DE REACCIÓN Y ANTICIPACIÓN & \\
\hline 6 & CAPACIDAD DE RECICLAJE & \\
\hline 7 & CAPACIDAD DE CONSENSO & \\
\hline 8 & DISCRECIÓN & \\
\hline 9 & TEMPLANZA & \\
\hline
\end{tabular}




\begin{tabular}{|r|l|l|}
\hline 10 & AMABILIDAD & \\
\hline 11 & FIRMEZA & \\
\hline 13 & PACIENCIA & \\
\hline 14 & CAPACIDAD DE IMPROVISACIÓN & \\
\hline 15 & BUENA PRESENCIA & \\
\hline 16 & HONRADEZ & \\
\hline 17 & CAPACIDAD DE LIDERAZGO & \\
\hline 18 & FLEXIBILIDAD & \\
\hline 19 & MANEJO DE VARIOS IDIOMAS & \\
\hline 20 & DINÁMICO & \\
\hline 21 & RESPETUOSO & \\
\hline 22 & DOTES COMUNICATIVAS (verbal/no verbal) & \\
\hline 23 & CORTÉS & \\
\hline 24 & SENTIDO COMÚN & \\
\hline 25 & GANAS DE TRABAJAR & \\
\hline 26 & SABER ESTAR & \\
\hline 27 & EFICAZ & \\
\hline 28 & ADAPTABILIDAD & \\
\hline 29 & CONOCIMIENTOS JURÍDICOS & \\
\hline 30 & ORGANIZADO & \\
\hline 31 & CAPACIDAD DE TRABAJO EN EQUIPO & \\
\hline 32 & SABER DELEGAR & \\
\hline 33 & TOLERANTE & \\
\hline 34 & CARISMÁTICO & \\
\hline 35 & FORMACIÓN UNIVERSITARIA & \\
\hline 36 & ESCUCHA ACTIVA & \\
\hline 37 & SENTIDO DEL HUMOR & \\
\hline
\end{tabular}

2.2 Los valores esenciales que se desprenden de la correcta aplicación de las normas de protocolo son la justicia y el orden

En total desacuerdo $\quad 1 \quad 2 \quad 2 \quad 3 \quad 4 \quad 5 \quad$ En total acuerdo

2.3 En los próximos años la profesión del protocolo requiere un reconocimiento oficial, a través de un estatuto jurídico que la defina.

En total desacuerdo $\quad 1 \quad 2 \quad 2 \quad 3 \quad 4 \quad 5 \quad$ En total acuerdo

2.4 El Protocolo debería poderse cursar como asignatura en los estudios universitarios de la rama de Ciencias Sociales. Indique por orden (del 1 al 6 siendo el 1 el puesto al que usted otorga más relevancia) de importancia que usted le otorgaría dentro de los planes de estudios de titulaciones superiores.

\begin{tabular}{|l|l|}
\hline Troncal & \\
\hline Libre configuración & \\
\hline Postgrados & \\
\hline Optativa & \\
\hline Obligatoria & \\
\hline No debería estudiarse & \\
\hline
\end{tabular}




\subsection{Estudio de la oferta de protocolo en las universidades}

\begin{tabular}{|c|c|c|c|c|}
\hline UNIVERSIDADES & $\begin{array}{r}\text { ESTUDIOS DE } \\
\text { COMUNICACIÓN }\end{array}$ & $\begin{array}{l}\text { ASIGNATURA } \\
\text { PROTOCOLO } \\
\text { (OP,LE,TR,OB) }\end{array}$ & $\begin{array}{l}\text { ESPECIALIZACIÓN } \\
\text { /POSTGRADO }\end{array}$ & TÍTULO DEL POSTGRADO \\
\hline A CORUÑA & NO & NO & NO & \\
\hline ALCALÁ & NO & NO & NO & \\
\hline ALICANTE & SI & SI & NO & \\
\hline ALMERÍA & NO & NO & NO & \\
\hline $\begin{array}{l}\text { AUTÓNOMA DE } \\
\text { BARCELONA } \\
\end{array}$ & SI & NO & NO & \\
\hline AUTÓNOMA DE MADRID & NO & NO & SI & \\
\hline BARCELONA & SI & NO & SI & \\
\hline BURGOS & NO & NO & NO & \\
\hline CÁDIZ & SI & NO & NO & \\
\hline CANTABRIA & NO & NO & NO & \\
\hline CARLOS III DE MADRID & SI & NO & NO & \\
\hline CASTILLA-LA MANCHA & NO & NO & NO & \\
\hline $\begin{array}{l}\text { COMPLUTENSE DE } \\
\text { MADRID }\end{array}$ & SI & SI & SI & $\begin{array}{l}\text { Gestión de Eventos Corporativos } \\
\text { (Logística, Seguridad y Protocolo) }\end{array}$ \\
\hline CÓRDOBA & NO & NO & NO & \\
\hline EXTREMADURA & SI & NO & NO & \\
\hline GIRONA & SI & NO & NO & \\
\hline GRANADA & NO & NO & NO & \\
\hline HUELVA & NO & NO & NO & \\
\hline ILLES BALEARS & NO & NO & NO & \\
\hline $\begin{array}{l}\text { INTERNACIONAL DE } \\
\text { ANDALUCÍA }\end{array}$ & NO & NO & NO & \\
\hline $\begin{array}{l}\text { INTERNACIONAL } \\
\text { MENÉNDEZ PELAYO }\end{array}$ & NO & NO & NO & \\
\hline JAÉN & NO & NO & NO & \\
\hline
\end{tabular}




\begin{tabular}{|c|c|c|c|c|}
\hline JAUME I DE CASTELLÓN & SI & SI & NO & \\
\hline LA LAGUNA & SI & NO & NO & \\
\hline LA RIOJA & NO & NO & NO & \\
\hline $\begin{array}{l}\text { LAS PALMAS DE GRAN } \\
\text { CANARIA }\end{array}$ & NO & NO & NO & \\
\hline LEÓN & NO & NO & NO & \\
\hline \multicolumn{5}{|l|}{ LLEIDA } \\
\hline MÁLAGA & SI & NO & SI & $\begin{array}{l}\text { Experto universitario en } \\
\text { comunicación, protocolo y } \\
\text { organización de actos institucionales } \\
\text { y corporativos }\end{array}$ \\
\hline $\begin{array}{l}\text { MIGUEL HERNÁNDEZ DE } \\
\text { ELCHE }\end{array}$ & SI & NO & SI & $\begin{array}{l}\text { Master en Protocolo, Comunicación } \\
\text { y Organización de Eventos }\end{array}$ \\
\hline MURCIA & SI & SI & NO & \\
\hline $\begin{array}{c}\text { NACIONAL DE } \\
\text { EDUCACIÓN A DISTANCIA }\end{array}$ & NO & NO & SI & Master en Protocolo \\
\hline OVIEDO & NO & NO & SI & $\begin{array}{l}\text { Especialista en protocolo y } \\
\text { ceremonial del estado e internacional } \\
\text { protocolo y Ceremonial }\end{array}$ \\
\hline PABLO DE OLAVIDE & NO & NO & NO & \\
\hline $\begin{array}{c}\text { PAÍS VASCO/EUSKAL } \\
\text { HERRIKO UNIBERTSITATEA }\end{array}$ & SI & NO & NO & \\
\hline $\begin{array}{l}\text { POLITÉCNICA DE } \\
\text { CARTAGENA }\end{array}$ & NO & NO & NO & \\
\hline $\begin{array}{l}\text { POLITÉCNICA DE } \\
\text { CATALUNYA }\end{array}$ & NO & NO & NO & \\
\hline POLITÉCNICA DE MADRID & NO & NO & NO & \\
\hline $\begin{array}{l}\text { POLITÉCNICA DE } \\
\text { VALENCIA }\end{array}$ & NO & NO & NO & \\
\hline POMPEU FABRA & SI & NO & NO & \\
\hline PÚBLICA DE NAVARRA & NO & NO & NO & \\
\hline REY JUAN CARLOS & SI & NO & NO & \\
\hline ROVIRA I VIRGILI & SI & NO & NO & \\
\hline
\end{tabular}




\begin{tabular}{|c|c|c|c|c|}
\hline SALAMANCA & SI & NO & NO & \\
\hline $\begin{array}{l}\text { SANTIAGO DE } \\
\text { COMPOSTELA } \\
\end{array}$ & SI & NO & NO & \\
\hline SEVILLA & SI & NO & NO & \\
\hline $\begin{array}{l}\text { VALENCIA ESTUDI } \\
\text { GENERAL }\end{array}$ & NO & NO & NO & \\
\hline VALLADOLID & SI & NO & NO & \\
\hline VIGO & SI & SI & NO & \\
\hline ZARAGOZA & NO & NO & NO & \\
\hline CATÓLICA DE ÁVILA & NO & NO & NO & \\
\hline $\begin{array}{l}\text { CATÓLICA DE VALENCIA } \\
\text { SAN VICENTE MÁRTIR } \\
\end{array}$ & NO & NO & NO & \\
\hline CATÓLICA SAN ANTONIO & SI & SI & SI & Experto universitario en protocolo \\
\hline DEUSTO & SI & NO & SI & $\begin{array}{l}\text { Master europeo en organización } \\
\text { de congresos, eventos y ferias }\end{array}$ \\
\hline NAVARRA & SI & NO & NO & \\
\hline PONTIFICIA COMILLAS & NO & NO & NO & \\
\hline $\begin{array}{l}\text { PONTIFICIA DE } \\
\text { SALAMANCA } \\
\end{array}$ & SI & NO & NO & \\
\hline ABAT OLIBA CEU & SI & NO & NO & \\
\hline A DISTANCIA DE MADRID & NO & NO & NO & \\
\hline ALFONSO X EL SABIO & NO & SI & NO & \\
\hline ANTONIO DE NEBRIJA & SI & NO & NO & \\
\hline CAMILO JOSÉ CELA & SI & NO & SI & $\begin{array}{l}\text { Experto en Organización de } \\
\text { Congresos y Actos Públicos }\end{array}$ \\
\hline $\begin{array}{l}\text { CARDENAL HERRERA- } \\
\text { CEU }\end{array}$ & SI & NO & NO & \\
\hline EUROPEA DE MADRID & SI & NO & NO & \\
\hline $\begin{array}{l}\text { EUROPEA MIGUEL DE } \\
\text { CERVANTES }\end{array}$ & SI & SI & NO & \\
\hline FERNANDO III & NO & NO & NO & \\
\hline FRANCISCO DE VITORIA & SI & SI & SI & $\begin{array}{l}\text { Master de técnico en protocolo y } \\
\text { relaciones institucionales del }\end{array}$ \\
\hline
\end{tabular}




\begin{tabular}{|c|c|c|c|c|}
\hline $\begin{array}{l}\text { INTERNACIONAL DE } \\
\text { CATALUNYA }\end{array}$ & SI & NO & NO & \\
\hline MONDRAGÓN & & & & \\
\hline UNIBERTSITATEA & SI & NO & NO & \\
\hline OBERTA DE CATALUNYA & SI & NO & NO & \\
\hline RAMÓN LLULL & SI & NO & NO & \\
\hline SAN JORGE & SI & SI & SI & $\begin{array}{l}\text { Experto universitario en Protocolo y } \\
\text { organización de actos }\end{array}$ \\
\hline SAN PABLO CEU & SI & SI & NO & \\
\hline S.E.K. & SI & NO & NO & \\
\hline VIC & SI & NO & NO & \\
\hline
\end{tabular}

